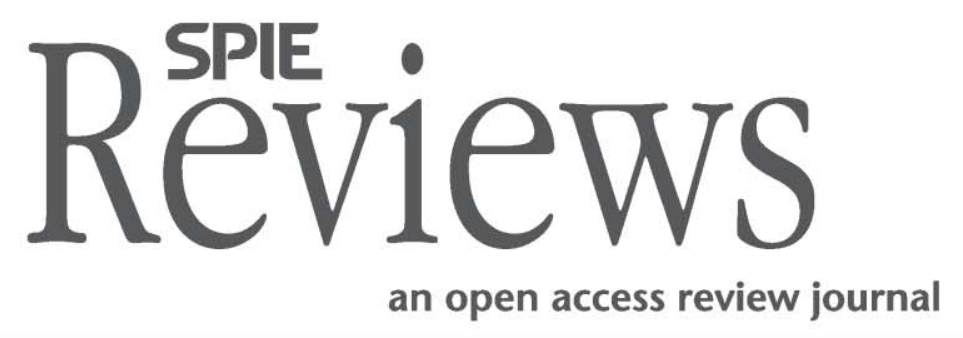

\title{
Review and evaluation of remote sensing methods for soil-moisture estimation
}

\author{
Amer Ahmad \\ Yun Zhang \\ Sue Nichols
}




\title{
Review and evaluation of remote sensing methods for soil-moisture estimation
}

\author{
Amer Ahmad, Yun Zhang, and Sue Nichols \\ University of New Brunswick, Department of Geodesy and Geomatics Engineering, \\ 15 Dineen Drive, Fredericton, New Brunswick E3B 5A3 Canada \\ a.ahmad@unb.ca
}

\begin{abstract}
Soil-moisture information plays an important role in disaster predictions, environmental monitoring, and hydrological applications. A large number of research papers have introduced a variety of methods to retrieve soil-moisture information from different types of remote sensing data, such as optical data or radar data. We evaluate the most robust methods for retrieving soil-moisture information of bare soil and vegetation-covered soil. We begin with an introduction to the importance and challenges of soil-moisture information extraction and the development of soil-moisture retrieval methods. An overview of soil-moisture retrieval methods using different remote sensing data is presented - either active or passive or a combination of both active and passive remote sensing data. The results of the methods are compared, and the advantages and limitations of each method are summarized. The comparison shows that using a statistical method gives the best results among others in the group: a combination of both active and passive sensing methods, reaching a 1.83\% gravimetric soil moisture (\%GSM) root-mean-square error (RMSE) and a 96\% correlation between the estimated and field soil measurements. In the group of active remote sensing methods, the best method is a backscatter empirical model, which gives a $2.32-1.81 \%$ GSM RMSE and a $95-97 \%$ correlation between the estimated and the field soil measurements. Finally, among the group of passive remote sensing methods, a neural networks method gives the most desirable results: a $0.0937 \%$ GSM RMSE and a $100 \%$ correlation between the estimated and field soil measurements. Overall, the newly developed neural networks method with passive remote sensing data achieves the best results among all the methods reviewed. ( 2011 Society of Photo-Optical Instrumentation Engineers (SPIE). [DOI: $10.1117 / 1.3534910]$
\end{abstract}

Keywords: soil moisture; group of remote sensing methods.

Paper 100111R received Jul. 21, 2010; revised manuscript received Oct. 26, 2010; accepted for publication Dec. 6, 2010; published online Feb. 28, 2011.

\section{Introduction}

\subsection{Importance of Soil-Moisture Information}

Estimating soil properties, including soil moisture, is important for many water-budgeting processes, and for meteorological and agricultural applications. ${ }^{1}$ Soil-moisture information can also be used as an indicator for the prediction of natural disasters, such as flooding and droughts, and for environment changing, such as dust storms and erosions. ${ }^{2}$ However, measuring accurate in situ soil moisture is too expensive because it requires a repeated sampling process to analyze the periodical changes in soil moisture. Moreover, the sampling itself may introduce problems, making the sampled data unreliable. ${ }^{3}$

Remote sensing has the ability to collect information from various samples over a large area in a short time and repeated time intervals, especially with recent developments in sensor functionality and both temporal and spatial image resolution.

$1946-3251 / 2011 / \$ 25.00$ @ 2011 SPIE 


\subsection{Challenges of Soil-Moisture Estimation}

The task estimating soil moisture becomes more difficult when the study area is a land covered with intense vegetation or snow and when there are significant topographical changes in the area. ${ }^{4,5}$ The most accurate results are achieved when there is no or low soil cover, especially when the test area is flat. By considering soil cover and topography as the main parameters that affect soil-moisture estimation, the question that must be answered is why does soil covered with vegetation or snow, and with topographical changes, cause difficulty in estimating soil moisture accurately.

The emitted electromagnetic radiation (in the passive remote sensing case) or the reflected microwave radiation (in the active remote sensing case) from the soil surface to the sensor represents the only measurement for studying the soil properties remotely. This emitted or reflected radiation from a covered soil surface to the remote sensor will no longer represent the actual soil surface emission because part of the emitted/reflected radiation might be either absorbed or enhanced by the soil cover. ${ }^{6}$ For topography, the surface roughness may be underestimated or overestimated because the surface will be either tilted toward or against the remote sensor. ${ }^{7}$ Therefore, spots located at changing ground topography may have different local incidence angles with respect to the sensor and might give unreal predictions.

From the remote sensing image interpretation point, when the value of a pixel has been acquired from a homogenous land cover, the value reflects the actual land cover where the pixel was captured. However, when a land area consists of a mixture of vegetation and bare soil cover, the acquired pixel's value would be reflected from a mix of both types of land cover. Heterogeneity is defined as consisting of elements that are not of the same kind or nature. ${ }^{8}$ Pixels' dissimilarity can be defined as a representation of different land covers within a pixel value. Captured pixels' values from different land cover cause confusion in assigning the exact pixel label to the right land cover, especially in a large-scale area. Additionally, different land cover reduces the classification accuracy of soil-moisture retrieval and mixed-pixel value has better accuracy and a lower root-mean-square error (RMSE) in soil-moisture classification. ${ }^{3,4}$

In terms of the soil-moisture estimation depth, remote sensing methods have been relatively successful in measuring the moisture at a depth of $5 \mathrm{~cm}$ from the top soil surface for bare soil or soil with less vegetation..$^{9-11}$ Meanwhile, estimating soil moisture at the root zone depth, 10 $\mathrm{cm}$ or more from the soil surface, can be considered as another challenge.

For brevity, a number of acronyms have been used in this paper and are defined as follows: moderate resolution imaging spectroradiometer (MODIS), synthetic aperture radar (SAR), advanced microwave scanning radiometer-EOS (AMSR-E), Earth Resources Satellite (ERS), pushbroom microwave radiometer (PBMR), Japanese Earth Resources Satellite (JERS), spaceborne imaging radar-C/X-band synthetic aperture radar (SIR-C/X-SAR), land surface temperature (LST), advanced land observing satellite-PRISM and AVNIR instruments additional to L-band SAR (ALOS-PALSAR), microwave imaging radiometer using aperture synthesis (MIRAS), tropical rainfall measuring mission/microwave imager (TRMM/TMI) remote sensing data, electrically scanning microwave radiometer (ESMR), Electro Magnetics Institute Radiometers (EMIRAD), and advanced space born thermal emission and reflection radiometer (ASTER).

\subsection{Sensors Development for Soil-Moisture Estimation}

Table 1 briefly describes the development of some of the satellites that have been widely used for soil moisture estimation since 1991.

\subsection{Purpose and Workflow of this Study}

Different soil-moisture evaluation methods have been introduced by different authors for different applications. The purpose of this study is to review, compare, and summarize existing 
Ahmad, Zhang, and Nichols: Review and evaluation of remote sensing methods for soil moisture estimation

Table 1 Satellites' sensor developments for soil-moisture estimation.

\begin{tabular}{|c|c|c|c|c|}
\hline Satellite & Sensor & Year launched & Owned by & Data type \\
\hline $\begin{array}{l}\text { Land sat } \\
\text { ESRI-1 }\end{array}$ & $\begin{array}{l}\text { Land sat } \\
\text { SAR-C-band }\end{array}$ & $\begin{array}{l}1975 \\
\text { July } 1991\end{array}$ & $\begin{array}{l}\text { NASA } \\
\text { European Space } \\
\text { Agency }\end{array}$ & $\begin{array}{l}\text { Passive } \\
\text { Active }\end{array}$ \\
\hline $\begin{array}{l}\text { JERS-1 } \\
\text { SIR-C/X-SAR }\end{array}$ & $\begin{array}{l}\text { SAR-L-band } \\
\text { SAR }\end{array}$ & $\begin{array}{l}\text { February } 1992 \\
\text { April } 1994\end{array}$ & $\begin{array}{l}\text { Japanese Agency } \\
\text { U.S-German- } \\
\text { Italian }\end{array}$ & $\begin{array}{l}\text { Active } \\
\text { Active }\end{array}$ \\
\hline ERS-2 & SAR & April 1995 & $\begin{array}{l}\text { European Space } \\
\text { Agency }\end{array}$ & Active \\
\hline RADARSAT-1 & SAR-C-band & $\begin{array}{l}\text { November } \\
1995\end{array}$ & $\begin{array}{l}\text { Canadian Space } \\
\text { Agency }\end{array}$ & Active \\
\hline Terra & $\begin{array}{l}\text { MODIS- Terra } \\
\text { ASTER- Terra }\end{array}$ & $\begin{array}{l}\text { December } \\
1999\end{array}$ & $\begin{array}{l}\text { NASA, partnerships } \\
\text { with the aerospace } \\
\text { agencies of Canada } \\
\text { and Japan. } \\
\text { NASA, partnerships } \\
\text { with the aerospace } \\
\text { agency of Japan. }\end{array}$ & Passive \\
\hline Aqua & $\begin{array}{l}\text { AMSR-E- Aqua } \\
\text { MODIS- Aqua }\end{array}$ & May 2002 & $\begin{array}{l}\text { NASA and the } \\
\text { National Space } \\
\text { Development } \\
\text { Agency (JAXA) of } \\
\text { Japan }\end{array}$ & Passive \\
\hline ALOS-PALSAR & $\begin{array}{l}\text { SAR L-band, } \\
\text { PRISM, and } \\
\text { AVNIR-2 } \\
\text { instrument }\end{array}$ & January 2006 & $\begin{array}{l}\text { National Space } \\
\text { Development } \\
\text { Agency of Japan }\end{array}$ & Passive + Active \\
\hline RADARSAT-2 & SAR-C-band & $\begin{array}{l}\text { December } \\
2007\end{array}$ & $\begin{array}{l}\text { Canadian Space } \\
\text { Agency }\end{array}$ & Active \\
\hline SMOS & $\begin{array}{l}\text { MIRAS } \\
\text { (interferometric } \\
\text { radiometer) } \\
\text { L-band }\end{array}$ & $\begin{array}{l}\text { November } \\
2009\end{array}$ & $\begin{array}{l}\text { European Space } \\
\text { Agency }\end{array}$ & Passive \\
\hline
\end{tabular}

methods to identify their effectiveness and weaknesses. The objective is to evaluate the methods that are applicable to land cover with mixed vegetation and bare soil.

The paper begins with an overview of the importance, challenges and development of soilmoisture information estimation using remote sensing. Then, an introduction to the remote sensing methods that are applied to soil-moisture information estimation from different satellite imagery is presented. This is followed by an overview of different methods, which are classified into three main groups based on the remote sensing data used: group of active remote sensing methods, group of passive remote sensing methods, and group of combined of active and passive remote sensing methods. Some methods are used commonly in all the three groups. A comparison of each group methods is then presented, and the most robust method of all groups is identified. Finally, the results are discussed and a conclusion is drawn. The information presented in this paper is shown in Fig. 1. The paper's main sections are drawn as trapezoidal shapes in the diagram, and the methods that are used in each remote sensing group are presented separately in rectangular shapes.

\section{Soil-Moisture Retreival Methods Using Remote Sensing}

Soil-moisture information can be retrieved from different remote sensing methods using different data, such as visible, infrared, thermal, and microwave data. ${ }^{12}$ Each remote sensing method used has its own advantages and disadvantages, based on how sensitive the soil surface is to 


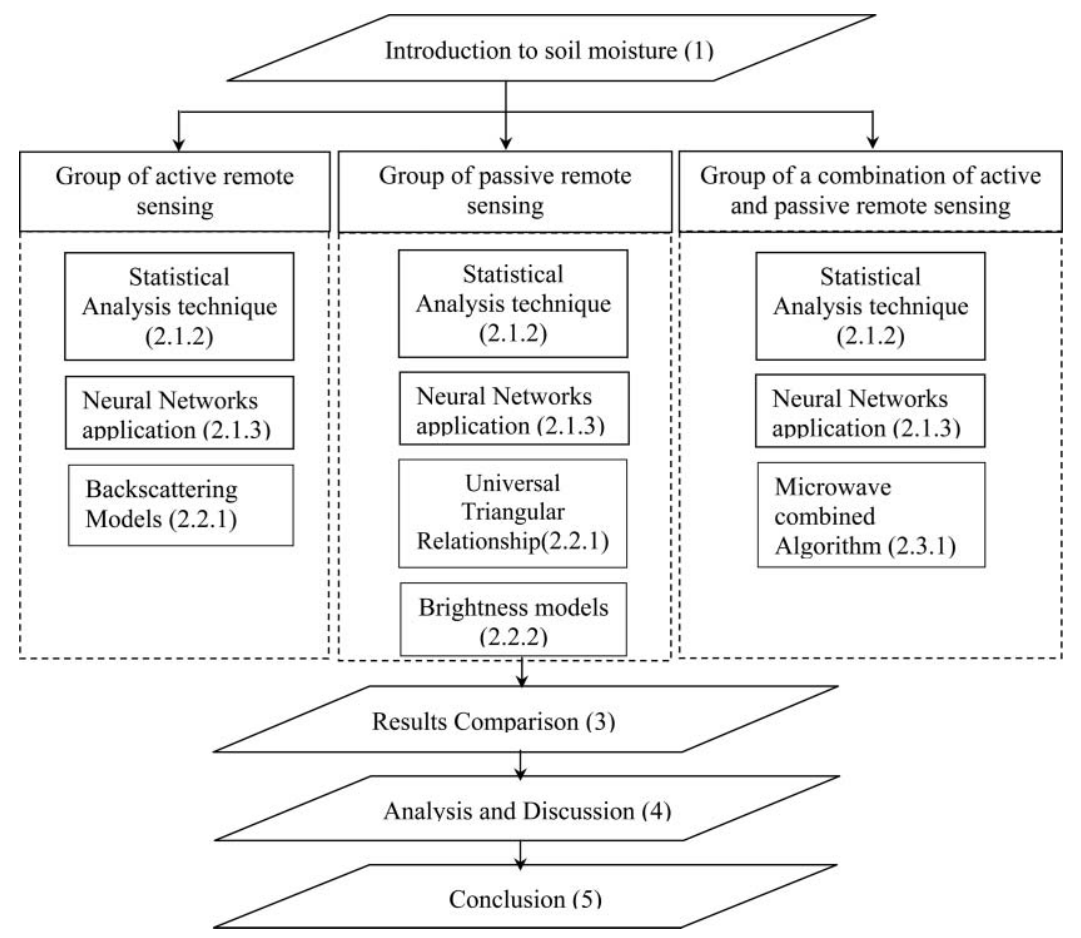

Fig. 1 Presentation of the paper's content.

the electromagnetic radiation and how strong the reflected radiation, from the soil surface, can be received by the sensor. To follow is an overview, including pros, cons, and a comparison among three different remote sensing group of methods that have been widely applied in field of soil-moisture estimation.

\subsection{Group of Active Remote Sensing Methods}

Electromagnetic microwave radiation with a wavelength that ranges between 0.5 and $100 \mathrm{~cm}$ has been used to measure soil characteristics using active remote sensing. The SAR sensor, an active remote sensor, is the most widely used sensor for soil-moisture estimation because of its ability to capture high-resolution images for soil-moisture retrieval based on the spatial variation in the ground soil moisture.

The operation's process is based on two main factors: sensor parameters and soil parameters. The sensor-parameter factor is represented by the variations in signal backscatter as a function of wavelength, incidence angle, and polarization. ${ }^{13,14}$ The soil-parameter factor is represented by the soil surface, the attenuation of the signal through the vegetation canopy, and the vegetation volume radiation backscatter. ${ }^{15}$ Normally, the lower the soil moisture content is in the soil surface, the stronger the radar backscatter value will be under the same land-cover conditions.

The backscatter signal $\left(\sigma^{\circ}\right)$ of an object is an amount of radiation reflected from the object's surface area and measured by a unit area in radar cross section. ${ }^{16}$ In other words, it represents the amount of measured microwave radiation that was sent originally by a radar sensor toward an object and then reflected from the object's surface area toward the radar sensor.

Like other active microwave sensors, SAR has the ability to penetrate the sublayer under the soil surface area. ${ }^{17}$ SAR provides high spatial resolution images, normally tens of meters. Furthermore, the technique of capturing SAR imagery is not influenced by weather conditions. However, it has a low revisit frequency and more sensitivity to soil roughness and vegetation. ${ }^{18}$ The following group of methods, which uses active remote sensing data, is widely used for 
soil-moisture estimation: backscattering models, statistical analysis technique, and neural networks application.

\subsubsection{Backscattering models}

The backscattered signal $\sigma^{\circ}$ is received by the radar sensor as an electromagnetic microwave emission. Then backscatter radiation is converted to decibel values using the following formula: ${ }^{19}$

$$
\sigma_{\mathrm{dB}}^{\circ}=10 \log _{10}\left(\sigma^{\circ}\right)
$$

For modeling the radar backscatter signal, three kinds of models have been used for soil-moisture estimation: empirical models, semi-empirical models, and theoretical models.

Empirical models. Empirical backscatter models result from several site experiment measurements of the backscatter signals $\left(\sigma^{\circ}\right)$ that are reflected from the soil surface to the radar sensor. The measured data are used to establish general boundaries or conditions that can be applied to obtain reasonably accurate soil-moisture results. ${ }^{20}$ However, empirical models may not be applicable when the set of conditions is changed, such as frequency, incidence angle, surface roughness, vegetation density, topography, etc. Therefore, they do not deliver desirable correlation results with the field measurement under a different set of conditions. ${ }^{21}$ Some empirical models are designed based on using different sensor polarization, which is either vertical or horizontal, to estimate soil roughness and soil moisture, such as Wang, ${ }^{22}$ Dubois et al., ${ }^{7}$ and Oh et al. ${ }^{21}$ models, and Zribi and Dechambre model. ${ }^{23}$

Theoretical model. Theoretical models are derived under restrictive theoretical basis to predict the general trend of radar backscatter in response to changes in soil roughness or soil moisture. ${ }^{15,20,22,24}$ Theoretical backscatter models are good for describing the soil surface properties based on a theoretical perspective. In addition, these models can be applied at different soil characteristics using different sensor properties. However, it is difficult for theoretical models to represent all the architecture of the vegetation canopy in one model; therefore, some models are designed to present only the leaf part, whereas others present only the branch part. ${ }^{25}$ Theoretical modeling is sensitive to surface soil roughness and vegetation, and small deviations in soil roughness can cause a large difference in the calculated backscatter; hence, these models are described as highly sensitive to signal backscatter. ${ }^{26}$ An example of widely used theoretical models is Kirchhoff model, which represents the relationship between a geometrical optics model and a physical optics model from radar backscatter. ${ }^{27}$ The Chen et al. model is another widely used theoretical model. ${ }^{28}$

Semi-empirical model. Semi-empirical models are derived from experimental data to develop empirical fitting of backscatter measurements for the soil surface. ${ }^{25}$ These models find an agreement between empirical models and theoretical models by having common rules derived from both models. Semi-empirical models provide a detailed description of radar backscatter of soil moisture, and they might be applied when little or no information about surface roughness for deriving these models is available. ${ }^{29}$

Oh proposed a semi-empirical model of the ensemble-averaged differential Mueller matrix, which uses backscatter signal on bare soil. ${ }^{30}$ The two other commonly used soil-moisture retrieval methods-statistical analysis technique and neural networks-are explained in Secs. 2.3.2 and 2.3.3, respectively.

\subsection{Group of Passive Remote Sensing Methods}

Modeling soil moisture using passive remote sensing information has made a large impact on mapping the global soil moisture because it is the best method for representing the global soilmoisture distribution. ${ }^{31}$ This group of methods retrieves soil-moisture information independently even when there is a vegetation canopy available, ${ }^{32}$ and it provides information about land 
properties, such as surface temperature and Normalized Difference Vegetation Index (NDVI). In addition, passive microwave systems have the ability to cover a large surface area with a low spatial resolution, normally tens of kilometers. However, some researchers imply that the optical/IR method has the advantage of providing fine spatial resolution for soil-moisture estimation. ${ }^{33}$ The thermal infrared remote sensing band, which ranges from 3 to $14 \mu \mathrm{m}$, is the electromagnetic wavelength that measures the land characteristics in this group of methods. These methods have proven their ability to retrieve soil-moisture information independently by providing direct measurements for soil moisture. ${ }^{34}$ The first attempt to estimate soil moisture from passive remote sensing information was proposed by Jackson, ${ }^{35}$ whose method was adopted to calculate soil-moisture retrieval at the top meters of the soil surface. Later, many applications were proposed based on establishing a relationship among land parameters, vegetation indices, and surface radiant temperature measurements. ${ }^{36,37}$ The following group of methods, which use passive remote sensing data, is widely used for soil-moisture estimation: universal triangular relationship method, brightness models, statistical analysis technique, and neural networks application.

\subsubsection{Universal triangular relationship method}

The universal triangular relationship is a widely used method for modeling different soilvegetation cover areas. It was proposed by Carlson ${ }^{34}$ and Owen et al., ${ }^{37}$ after they had conducted many trial experiments.

The method shows that there is a universal relationship among soil moisture, NDVI, and LST of a given region. The shape of the relationship is triangular or slightly truncated trapezoidal (Fig. 2). The ellipsoid shape drawn at the upper left edge of the triangle is represented by pixels having commonly low ground moisture content with low vegetation and high temperature called the "dry edge," and most of these pixels lie on bare soil. The ellipsoid shape drawn in the middle zone area represents by pixels that lie in a partially vegetated cover area and have commonly low moisture content with an average temperature. The lower right edge ellipsoid represents by pixels that lie in a vegetation covered area with high soil moisture and low temperature called, the "wet edge." Hence, every captured pixel will be presented within the range between the warm edge and the wet edge of the drawn triangle, and located depending on how moist and vegetated the area is.

The relationship among the three parameters is presented in the following regression formula: ${ }^{33}$

$$
M=\sum_{i=0}^{i=n} \sum_{J=0}^{j=n} a_{i j} \operatorname{NDVI}^{*(i)} \mathrm{T}^{*(j)},
$$

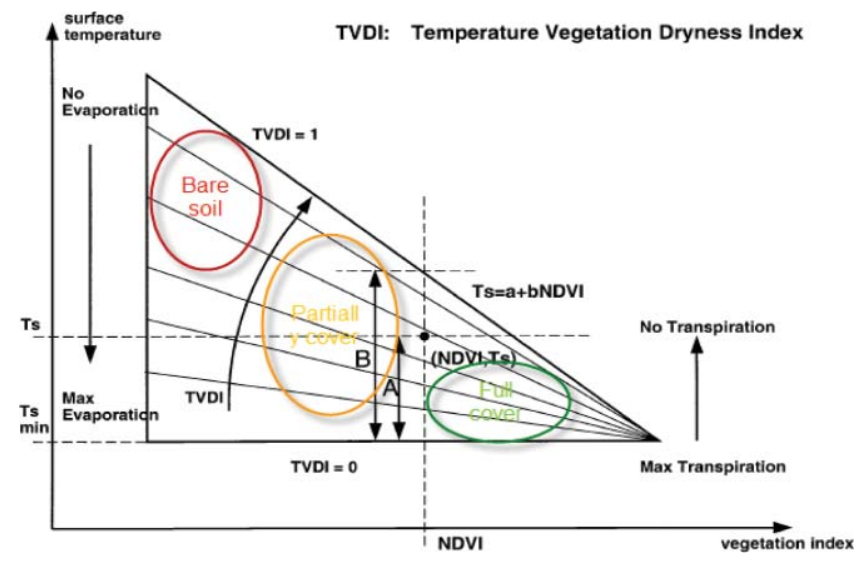

Fig. 2 NDVI-T $T_{s}$ representation for universal triangular method (Ref. 38). 
where $a_{i j}$ is the regression coefficient. The method is widely applicable to any land that has bare soil and vegetation cover. ${ }^{38}$

Although the method is based on optical remote sensing data, which is influenced by atmospheric conditions, the universal method is insensitive to surface conditions, atmosphere, and net radiation. ${ }^{34}$ Furthermore, the method requires a simple process to extract the ground soil-moisture information using passive land parameter data. ${ }^{33}$

Recently, the universal method has been modified by redefining the slope of the wet edge line from a horizontal, which has a zero slope, to a nonhorizontal slope; ${ }^{34}$ however, the overall shape is still triangular. Other indexes have been derived based on the method's principles, such as temperature vegetation water index (TVWI) ${ }^{39}$ Many other studies have followed this method, such as the methods of Sandholt et al..$^{38}$ and Wang et al. ${ }^{33}$ The method's limitation is that it is affected by topographic changes; therefore, the land surface where the triangular shape will be identified must be flat. ${ }^{34}$

\subsubsection{Brightness models}

Brightness models, also called radiometric models, give better estimation results on bare soil because the surface emission radiation reflects the soil's dielectric properties. Brightness temperature $\left(T_{\mathrm{B}}\right)$ represents the model's main input parameter; $T_{\mathrm{B}}$ is the amount of measured radiation, in terms of temperature, from an object's surface to the sensor. Additional data such as the vegetation parameters and the surface parameters (e.g., bulk density and soil texture) can be added to improve the model's output results. Another important soil parameter that affects these models is the soil roughness, which is represented by root-mean-square (RMS) height and the correlation length. ${ }^{1-40}$

Compared to the modeling applications, radiometric models are relatively easy to implement and don not need field experiments. ${ }^{41}$ However, their use is more limited to a specific case or available data. Many brightness algorithm models were proposed for retrieving soil moisture from passive data. ${ }^{42-44}$ The model of Shi et al. is another example based on the relationship between surface microwave brightness temperature and the physical surface temperature. ${ }^{45}$ The other two commonly used methods, which are statistical analysis technique and neural networks application, will be explained in Secs. 2.3.2 and 2.3.3.

\subsection{Group of Combined Active and Passive Remote Sensing Methods}

As remote sensor instruments and space craft have been developed, integrating both active and passive remote sensing information with their particular strengths and weaknesses, has become worthwhile. Thus, combining high spatial resolution information from active remote sensing with high temporal resolution information from passive remote sensing on an extended area has improved the soil-moisture estimation accuracy. In addition, the revolution of developing advanced spacecrafts, which are designed to carry multisensor instruments, both passive and active, enabled integrating both data together in one system, such as ALOS-PALSAR and the Soil Moisture Active and Passive (SMAP) mission (planned to be launched in 2014). The first implemented algorithm that used the advantages of this method was implemented by O'Neill. ${ }^{46}$ It has been found that the results improved substantially as compared to using each type of data individually. As a result, many researchers follow the technique of integrating both active and passive methods for soil-moisture estimation. The most widely used group of methods, which combines both active and passive data, is as follows: microwave combined algorithms, statistical analysis technique, and neural networks application.

\subsubsection{Microwave combined algorithms}

Normally, soil-moisture estimation algorithms analyze the pixels' digital number (DN) after making sure that the effects of atmosphere, vegetation, geometry, soil properties, and sensor 
configurations have been corrected. Later, the algorithm that establishes an objective relationship between the estimated and field soil-moisture measurements may be initiated.

Integrating information from both passive and active remote sensing data in a complementary way to reach a new level of accurately estimated results is the main aim of this methodology. A combined algorithm includes input parameters extracted from active remote sensing, such as vegetation and surface roughness, and parameters extracted from passive remote sensing, such as brightness temperature $\left(T_{\mathrm{B}}\right)$. In most cases, the algorithm also considers essential soilmoisture parameters that affect the estimated soil-moisture accuracy, such as optical depth and surface roughness. ${ }^{47}$

A workshop report released by the NASA Soil Moisture community for the Active/Passive (SMAP) Mission implies that combined algorithms are not as robust as the brightness passive algorithms. ${ }^{48}$ However, combining active with passive methods, such as SAR and radiometer, can reduce soil-moisture prediction errors to $\pm 30 \%$ of the true field capacity. ${ }^{49}$

\subsubsection{Statistical analysis technique}

All kinds of remote sensing data that have been mentioned above can be used in the methods for soil-moisture estimation. This method uses statistical calculations on the data to draw a relationship between two variables: the estimated soil moisture from the remote sensing information and the field soil moisture. Most of this statistical analysis is represented by a linear regression analysis, which is widely used between the two variables. ${ }^{50}$ Many statistical methods that have been implemented to retrieve soil moisture are based on converting the emitted microwave radiation, from the surface to the sensor, into mathematical values that can be statistically analyzed. ${ }^{51,52}$ The regression analysis aims to measure the degree of linear correlation between the two variables. The more linearly the relationship is drawn, the better the accuracy and correlation between the estimated soil moisture and the measured soil moisture can be determined. Saleh et al. proposed a regression analysis method based on the regression method to form a relationship between the L-band emission of the biosphere model (L-MEB) and the retrieved soil moisture using a semi-empirical regression method. ${ }^{53}$ Another statistical retrieval method was presented by Pellarin et al.; it was aimed at finding the relationship between $T_{\mathrm{B}}$ and the retrieved soil moisture. ${ }^{54}$

\subsubsection{Neural networks application}

Neural networks are an artificial intelligence technique that consists of a set of mathematical functions that complement each other to produce a desirable output result. Several studies describe a neural networks application as an inverse model because it converts the input information into desirable output results. ${ }^{50,55,56}$ Neural networks are based on a series of complex mathematical equations applied to the network's input parameters to deliver desirable output results. Neural networks applications are widely used in different fields of science, such as medical applications, weather forecast, and other computer applications.

In the field of remote sensing, one of the most important kinds of neural networks is the back-propagation network due to the application's ability to produce more desirable results. For soil-moisture estimation, information from both active and passive remote sensing has shown desirable results using this method.

The methodology's drawback is that under a vegetated area, the neural networks application gives inaccurate results due to a lack of correlation between the backscattered radiation and the in situ soil measurements. ${ }^{57}$ Furthermore, the neural networks application has a complex computation network to design a desirable correlation between the input and output results because the application is highly sensitive to the input parameters. ${ }^{58}$ As a result, it requires the user's experience to integrate adequate input parameters and carefully choose the acquired training pixels without overtraining to get better output accuracy. 
Ahmad, Zhang, and Nichols: Review and evaluation of remote sensing methods for soil moisture estimation

Table 2 Results of group of combined active and passive remote sensing methods.

\begin{tabular}{lccc}
\hline \hline Refs. & Methodology & RMSE (\%GSM) & CR\% \\
\hline 47 & Microwave combined algorithm & Retrieval algorithm \\
Inverse model & 3.16 for ESTAR \\
59 & 3.78 for SAR & Minimum of 93 \\
60 & Bayesian inversion model & & 68 for C-band \\
& Fuzzy logic & 3.39 & 60 for L-band \\
4 & + & & \\
& Neural networks & 5.5 & 77 \\
58 & Neural networks & 6.44 & \\
57 & Neural networks & & \\
& Fuzzy logic & 6.97 & 96 \\
51 & Statistical regression analysis & 1.83 & 67 \\
& Statistical regression analysis & 2.63 & 90 \\
& Passive physical model & 2.23 & 64 \\
\hline \hline
\end{tabular}

Wignerona et al. describe neural networks application as a simple and efficient method in passive remote sensing observations for soil-moisture estimation, and they imply that the application can only be limited for the regions and time period during which they were calibrated. ${ }^{50}$

\section{Results Comparison}

In order to evaluate the accuracy of each soil-moisture estimation method, a general statistical analysis based on the correlation coefficient (CR) and/or the standard deviation (RMSE) was conducted in Tables $2-4$. The analysis was compared between the estimated result and the corresponding field measurement. A linear correlation between the estimated result and the field data was drawn in a two-dimensional scatter plot, and then the correlation coefficient was calculated. When the correlation coefficient is high and the standard deviation is low, the method is considered robust and the analysis result is more desirable, and vice versa.

The comparison process is implemented based on classifying the group of methods based on the remote sensing data used: the active remote sensing group, the passive remote sensing group, and a combination of active and passive remote sensing group. On the basis of the statistical analysis that is shown in Tables 2-4, the most robust method in each group was chosen, and then the best method among the chosen methods was identified as the most successful method.

The CR of each method was calculated based on the number of soil samples measured and the corresponding number of correspondent points in the analysis results. In Tables $2-4$, the

Table 3 Results of group of active remote sensing methods.

\begin{tabular}{llcc}
\hline \hline Refs. & Methodology & RMSE (\%GSM) & CR\% \\
\hline & & & 89 \\
& & & $\begin{array}{c}\text { For bare soil } \\
75\end{array}$ \\
61 & An empirical model & & $\begin{array}{c}\text { For vegetated soil } \\
83\end{array}$ \\
& & & For combined data \\
62 & An empirical model + A nonlinear least square method & $2.32-1.81$ & $95-97$ \\
63 & A backscatter theoretical model & & 96 \\
& & & For Sandy soil \\
7 & An empirical algorithm & & 97 \\
64 & Neural networks & $<4.2$ & For loess Soil \\
\hline \hline
\end{tabular}


Table 4 Results of group of passive remote sensing methods.

\begin{tabular}{llcc}
\hline \hline Refs. & Methodology & RMSE (\%GSM) & CR\% \\
\hline 34 & Universal Triangular Relationship & $<0.07$ & $40-96$ \\
65 & Analytic algorithm & - & 80 \\
66 & Neural networks + a land surface process/radio brightness model & 0.0937 & 1 \\
44 & Algorithm & 2.56 & 71.6 \\
67 & Transfer Model (Emission model) & 84 \\
\hline \hline
\end{tabular}

land cover conditions and the surface parameters considered for each study area are identified for each reference.

Table 5 contains more detailed information about the soil cover types of the study area as well as the soil parameters that are considered in each paper presented in Tables 2-4. For instance, some researchers considered vegetation parameters or topography changes to determine their effect on the estimated results, whereas others did not.

\section{Analysis and Discussion}

Results from a number of soil-moisture estimation methodologies are compared according to the data used under a similar land cover, which is bare and vegetation-covered soil. In all cases, each author found his/her proposed method works well compared to other selected methods. The comparison guides among the different methods in each group are based on statistical parameters, such as a correlation coefficient and/or an RMSE between the methods' estimated results and the field measurements. On the basis of the difference in soil parameters considered in each methodology, such as the area's topography and vegetation density, it is difficult to draw an absolute conclusion about which one is the best or worst. However, each method to estimate soil moisture is fairly applicable in different areas because it is applicable under different land conditions. Land-cover conditions have a substantial effect on the final soil-moisture information estimation because of the significant effect of vegetation on the sensor's backscatter radiation.

In addition, different methods use different ways of collecting the in situ soil measurements, and the number of collected soil measurements in each method is different from others. Therefore, in each reference presented, the statistical parameters were calculated based on the number of collected measurements. Moreover, the numbers of collected measurement might affect the calculated statistical parameters. For instance, a few numbers of collected measurements might give a higher correlation with the estimated points, when the number of measurements increases, the correlation coefficient might decrease.

On the basis of the presented statistical parameters, the methods can be ranked from the lowest RMSE and higher CR, which is the most robust method to the higher RMSE and lower $\mathrm{CR}$, which is the less robust method. However, other parameters, such as the difference in the method of collecting the measurement and the difference in the number of measurements that are used to calculate the statistical parameter, could cause inaccuracies in ranking the methods.

On the basis of the statistical parameter values that are presented in Tables $2-4$, some general observations can be made for each group of methods used. First, among the active remote sensing group, the radar backscatter modeling method gives desirable estimation results. Second, neural networks modeling gives a better result compared to other groups of passive remote sensing methods, and its result is the best among all methods.

Third, a statistical analysis method on data captured from soil-moisture satellites, such as PALS, has delivered highly correlated results for soil-moisture estimation using data captured by radiometric passive channels rather than scaterometer channels. Additionally, ground soil measurements at a depth of a few centimeters $(0-1 \mathrm{~cm})$ from the field surface layer give better correlation with the estimated soil moisture compared to the ground measurements at deeper layers. Fourth, in bare soil, using active remote sensing gives a more accurate correlation result 


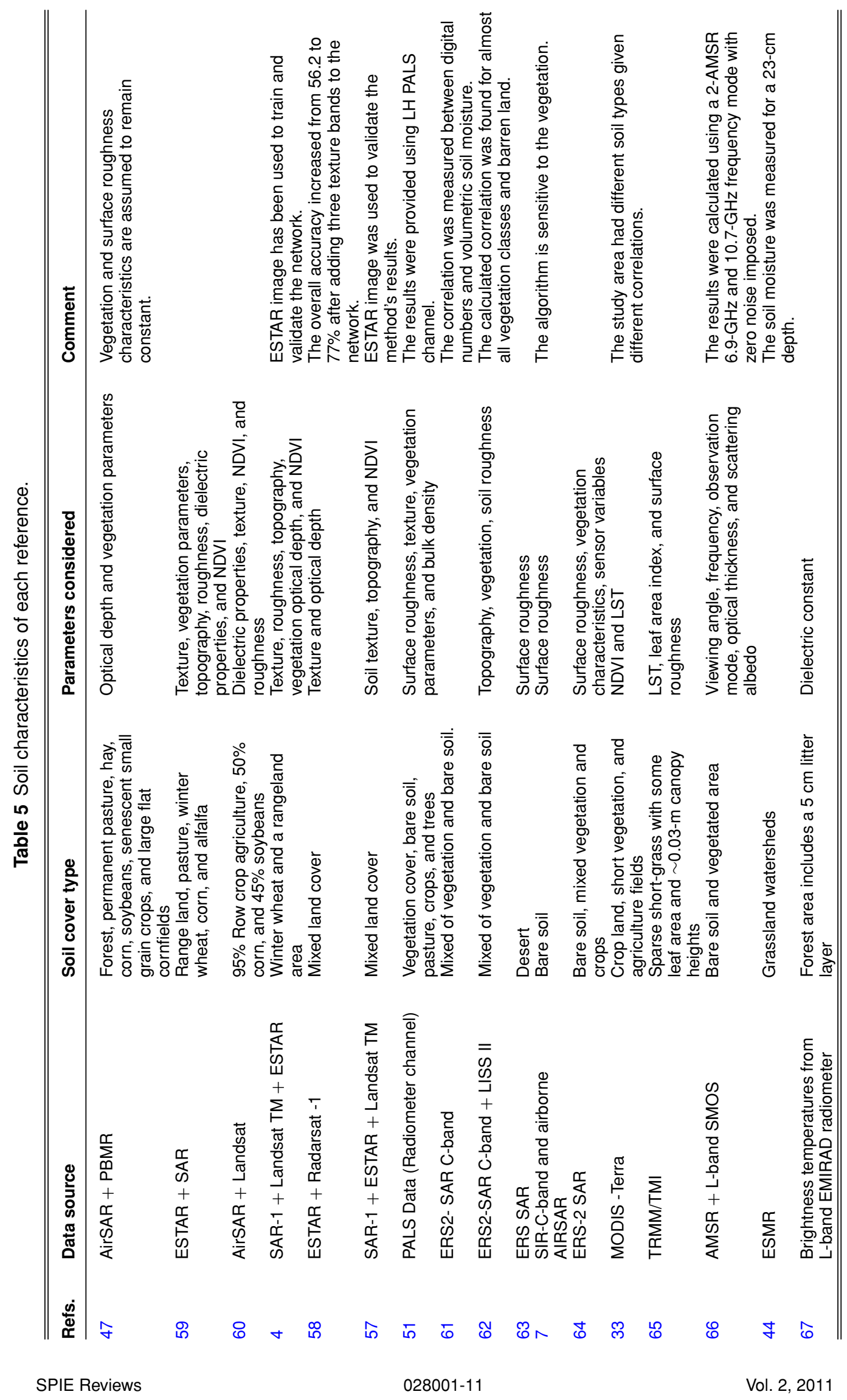


with the field soil measurements than all other methods, without necessarily considering the soil-roughness effect.

Finally, the surface scattering method in bare soil is usually related to geometric and dielectric properties, which substantially affects the backscattered radiation response. Moreover, correcting the vegetation optical parameters plays a significant role in increasing the moisture estimation accuracy of a vegetation-covered soil.

From the above-mentioned observations, a few general recommendations can be made. If both sensor parameters and land-cover properties are important for having highly accurate results, a relationship between these two main variables needs to be drawn. Moreover, based on the results compared above, for a vegetation-covered soil, the most accurate result is found when the neural networks application is used. Although all the mentioned methodologies have the capability to retrieve soil moisture at certain conditions and have their strengths and weaknesses, estimating soil moisture using remote sensing cannot be replaced by the actual soil field measurements.

\section{Conclusion}

In this study, an assessment of the current methodologies for soil-moisture estimation was performed based on their common soil cover conditions. Other soil surface parameters, which are not considered in this comparison, might affect the comparison results, such as the topographical area, the method of collecting the field measurements, and the number of collected in situ measurements. Some of those parameters have not been considered in this study because either they were unknown or were neglected and no correction was made to consider their effect. Therefore, vegetation parameters received more attention than topography parameters.

At present, remote sensing methods have not been successful in estimating soil moisture from deep soil layers, such as at the root-zone soil layers. However, the ability to retrieve soil-moisture information from the surface layers in itself needs to be further investigated. Although in situ soil-moisture measurements might involve sampling errors, they are considered the standard measurements for soil-moisture estimation, and remote sensing information estimations are usually compared to the sampling measurements.

On the basis of the active remote sensing methods, estimating soil moisture on bare soil or soil with less vegetation gives more accurate results, as compared to using the methods on a mixture of land-cover soil. Moreover, the estimation process becomes more challenging when the vegetation cover is dense. From the other side, under similar soil cover conditions, retrieving soil moisture using a combination of both active and passive soil information gives reasonably accurate results. Applications that use a combination of both active and passive remote sensing information have promising results. Processing the captured microwave signal to convert it to mathematical values, implementing a mathematical algorithm or a model to correct the soil surface and sensor parameters, and then analyzing the output results using a statistical method are the main processing steps for the most widely used methodologies.

\section{Acknowledgments}

The author thanks the Iraqi Ministry of Higher Education for its sponsorship, and Krista Amolins, a PhD student at the Geodesy and Geomatics Engineering/ University of New Brunswick, for her support and feedback to make this paper better.

\section{References}

1. N. E. C. Verhoest, H. Lievens, W. Wagner, J. Álvarez-Mozos, M. S. Moran, and F. Mattia, "On the soil roughness parameterization problem in soil moisture retrieval of bare surfaces from synthetic aperture radar," Sens. J. 8, 4213-4248 (June 2008). 
2. Canada Center for Remote Sensing, "Fundamentals of remote sensing applications," February 2008, http://www.ccrs.nrcan.gc.ca/resource/tutor/fundam/chapter5/14_e.php (May 2010).

3. T. Lakhankar, H. Ghedira, A. Azar, and R. Khanbilvardi, "Effect of sub-pixel variability and land-cover on soil moisture retrieval from RADARSAT-1 data," IEEE MicroRad, pp. 187-192 (March 2006).

4. T. Lakhankar, H. Ghedira, M. Temimi, A. E. Azar, and R. Khanbilvardi, "Effect of land cover heterogeneity on soil moisture retrieval using active microwave remote sensing data," J. Remote Sens. 1, 80-91 (2009).

5. M. J. Sandells, Ian. J. Davenport, and R. J. Gurney, "Passive L-band microwave soil moisture retrieval error arising from topography in otherwise uniform scenes," $A d v$. Water Resources 31, 1433-1443 (2008).

6. Y. Du, F. T. Ulaby, and M. C. Dobson, "Sensitivity to soil moisture by active and passive microwave sensors," IEEE Trans. Geosci. Remote Sens. J. 38(1), 105-113 (January 2000).

7. P. C. Dubois, J. Zyl, and T. Engman, "Measuring soil moisture with imaging radars," IEEE Trans. Geosci. Remote Sens. J. 33(4), 915-926 (July 1995).

8. G. A. Miller, "WordNet Open Sourc," Princeton University, http://wordnetweb.princeton .edu/perl/webwn?s=heterogeneous (December 2009).

9. T. J. Jackson, J. Schmugge, and E. T. Engman, "Remote sensing applications to hydrology: soil moisture," J. Hydrol. Sci. 41(4), 517-529 (August 1996).

10. S. C. Dunne, D. Entekhabi, and E. G. Njoku, "Impact of multiresolution active and passive microwave measurements on soil moisture estimation using the ensemble Kalman smoother," IEEE Trans. Geosci. Remote Sens. J. 45(4), 1016-1028 (April 2007).

11. N. S. Chauhan, S. Miller and P. Ardanuy, "Spaceborne soil moisture estimation at high resolution: A microwave optical/IR synergistic method," Int. J. Remote Sens. 24(22), 45994622 (November 2003).

12. P. P. Batlivala and F. T. Ulaby, "Feasibility of monitoring soil moisture using active microwave remote sensing," University of Kansa Center for Research, Inc., Remote Sensing Laboratory Technical Report No. 264-12 (1977).

13. N. Baghdadi, M. Zribi, C. Loumagne, P. Ansart, and T. P. Anguela, "Analysis of Terra SAR-X data and their sensitivity to soil surface parameters over bare agricultural fields," Remote Sens. Env. 112, 4370-4379 (2008).

14. A. M. Smith, K. Scipal, and W. Wagner, "Active sensor system for drought stress monitoring," Agriculture and Agri-Food Canada Lethbridge, Alberta, Canada and Institute of Photogrammetry and Remote Sensing at University of Technology, Vienna.

15. F. T. Ulaby, P. C. Dubois, and V. J. Zyl, "Radar mapping of surface soil moisture," J. Hydrol. 184, 57-84 (1996).

16. W. Wagner, "Soil moisture retrieval from ERS scatterometer data", $\mathrm{PhD}$ dissertation, Vienna university of technology, Karlsplatz, Wien, Austria (December 1998).

17. G. L. Prost, Remote Sensing for Geologists: A Guide to Image Interpretation, 2nd ed., Gordon and Breach, New York (2001).

18. L. Wang and J. J. Qu, "Satellite remote sensing applications for surface soil moisture monitoring: a review," Front. Earth Sci. Chin. J. 3(2), 237-247 (2009).

19. N. Baghdadi, M. Aubert, O. Cerdan, L. Franchistéguy, C. Viel, Eric Martin, M. Zribi, and J. F. Desprats, "Operational mapping of soil moisture using synthetic aperture radar data: application to the touch basin (France)," Sensors J. 7, 2458-2483 (October 2007).

20. J. P. Walker, P. R. Houser, and G. R. Willgoose, "Active microwave remote sensing for soil moisture measurement: a field evaluation using ERS-2," Hydrol. Process. 18, 1975-1997 (2004).

21. Y. Oh, K. Sarabandi, and F. T. Ulaby, "An empirical model and an inversion technique for radar scattering from bare soil surfaces," IEEE Trans. Geosci. Remote Sens. J. 30(2), 370-381 (1992). 
22. W. Xiao and Z. Zengxiang "A review: Theories, methods and development of soil moisture monitoring by remote sensing," IEEE Int. Geosci. Remote Sens. J. 6, 4505-4507 (2005).

23. M. Zribi and M. Dechambre, "A new empirical model to retrieve soil moisture and roughness from C-band radar data," Remote Sens. Env. 84, 42-52 (2002).

24. F. T. Ulaby, P. C. Dubois, and J. Zyl, "Radar mapping of surface soil moisture," J. Hydrol. 184, 57-84 (1996).

25. R. Bindlisha, and A. P. Barros, "Parameterization of vegetation backscatter in radar-based, soil moisture estimation," Remote Sens. Env. J. 76, 130-137 (2001).

26. D. P. Thoma, M. S. Moran, R. Bryant, M. Rahman, C. D. Holifield-Collins, S. Skirvin, E. E. Sano, and K. Slocum, "Comparison of four models to determine surface soil moisture from C-band radar imagery in a sparsely vegetated semiarid landscape," Water Resources Res. 42, W01418 (2006).

27. M. C. Dobson and F. T. Ulaby, "Active microwave soil moisture research," IEEE Trans. Geosci. Remote Sens. J. GE-24(1), 23-36 (January 1986).

28. K. S. Chen, T. Wu, L. Tsang, Q. Li, J. Shi, and A. K. Fung, "Emission of rough surfaces calculated by the integral equation method with comparison to three-dimensional moment method simulations," IEEE Trans. Geosci. Remote Sens. J. 41(1), 90-101 (January 2003).

29. G. D'Ursoa and M. Minacapilli, "A semi-empirical approach for surface soil water content estimation from radar data without a priori information on surface roughness," $J$. Hydrol. 321, 207-310 (2006).

30. Y. Oh, K. Sarabandi, and F. T. Ulaby, "Semi-empirical model of the ensemble-averaged differential Mueller matrix for microwave backscattering from bare soil surfaces," IEEE Trans. Geosci. Remote Sens. J. 40(6), 1348-1355 (June 2002).

31. J. P. Walker and P. R. Houser, "A methodology for initializing soil moisture in a global climate model: Assimilation of near-surface soil moisture observations," J. Geophys. Res. 106(D11), 11761-11774 (June 2001).

32. T. J. Jackson and T. J. Schmugge, "Vegetation effects on the of soils microwave emission," Remote Sens. Env. 36, 203-212 (1991).

33. L. Wang, J. J. Qu, S. Zhang, X. Hao, and S. Dasgupta, "Soil moisture estimation using MODIS and ground measurements in eastern China," Int. J. Remote Sens. 28(6), 1413-1418 (March 2007).

34. T. Carlson, "An overview of the "triangle method" for estimating surface evapotranspiration and soil moisture from satellite imagery," Sens. J. 7, 1612-1629 (2007).

35. J. P. Walker, P. A. Troch, M. Mancini, G. R. Willgoose and J. D. Kalma, "Profile soil moisture estimation using the modified IEM," Geosci. Remote Sens. 3, 1263-1265 (1997).

36. B. J. Choudhury, Y. H. Kerr, E. G. Njoku, and P. Pampaloni, Passive Microwave Remote Sensing of Land-Atmosphere Interactions, VSP, Utrecht, The Netherlands (1995).

37. T. W. Owen, T. N. Carlson, and R. R. Gillies, "An assessing soil moisture of satellite remotely-sensed land cover parameters in quantitatively describing the climatic effect of urbanization," Int. J. Remote Sens. 19(9), 1663-1681 (1998).

38. I. Sandholt, K. Rasmussen, and J. Andersen, "A simple interpretation of the surface temperature/vegetation index space for assessment of surface moisture status," Remote Sens. Env. 79, 213-224 (2002).

39. Q. K. Hassan, C. P.-A.Bourque, F. Meng and R. M. Cox, "A wetness index using terraincorrected surface temperature and normalized difference vegetation index derived from standard MODIS products: An evaluation of its use in a humid forest-dominated region of eastern Canada," Sens. J. 7(10), 2028-2048 (2007).

40. M. Nishimoto, "Error analysis of soil roughness parameters estimated from measured surface profile data," IEEE Xplore J. II, 719-722 (July 2008).

41. T. J. Jackson, "Measuring surface soil moisture using passive microwave remote sensing," Hydrol. Process. J. 7, 139-152 (1993). 
42. R. Bindlish, T. J. Jackson, E. Wood, H. Gao, P. Starks, D. Bosch, and V. Lakshmi, "Soil moisture estimates from TRMM microwave imager observations over the southern United States," Remote Sens. Env. 85(4), 507-515 (February 2003).

43. T. J. Jackson, D. M. Le Vine, A. Y. Hsu, A. Oldak, P. J. Starks, C. T. Swif, J. D. Isham, and M. Haken, "Soil moisture mapping at regional scales using microwave radiometry: the southern great plains hydrology experiment," IEEE Trans. Geosci. Remote Sens. J. 37(5), 2136-2151 (September 1999).

44. B. J. Blanchard, M. J. McFmland, T. J. Schmugge, and E. Rhoades, "Estimation of soil moisture with API algorithms and microwave emission," Water Resources Bull. Am. Water Resources Assn. 17(5), 767-774 (October 1981).

45. J. Shi, L. Jiang, L. Zhang, K. S. Chen, J. Wigneron, A. Chanzy, and T. J. Jackson, "Physically based estimation of bare-surface soil moisture with the passive radiometers," IEEE Trans. Geosci. Remote Sens. J. 44(11) 3145-3153 (November 2006).

46. P. E. O'Neil, "Use of active and passive microwave remote sensing for soil moisture estimation through corn," Int. J. Remote Sens. 17(10), 1851-1865 (1996).

47. N. S. Chauhan, "Soil moisture estimation under a vegetation cover: Combined active passive microwave remote sensing method,"Int. J Remote Sens. 18(5), 1079-1097 (1997).

48. NASA, "Soil moisture active/passive (SMAP) Mission," Workshop Report, http://nasascience.nasa.gov/earth-science/decadal-surveys/Volz1_SOIL MOISTUREAP_ 11-20-07.pdf (December 2009).

49. F. T. Ulbay, M. C. Dobson, and D. R. Brunfeldt, "Improvement of moisture estimation accuracy of vegetation-covered soil by combined active/passive microwave remote sensing," IEEE Trans. Geosci. Remote Sens. J. GE-21(3), 300-307 (1983).

50. J.-P. Wignerona, J.-C. Calvetb, T. Pellarinb, A. A. Van de Griendc, M. Bergerd, and P. Ferrazzolie, "Retrieving near-surface soil moisture from microwave radiometric observations: current status and future plans," Remote Sens. Env. 85, 489-506 (2003).

51. J. D. Bolten, V. Lakshmi, and E. G. Njoku, "Soil moisture retrieval using the passive / active L- and S-Band radar/ radiometer," IEEE Trans. Geosci. Remote Sens. J. 41(12), 2792-2801 (2003).

52. E. M. Sanden, C. M. Britton, and J. H. Everitt, "Total ground-cover estimates from corrected scene brightness measurements," Photogram. Eng. Remote Sen. 62(2),147-150 (February 1996).

53. K. Saleh, J. Wigneron, P. de Rosnay, J. Calvet, and Y. Kerr, "Semi-empirical regressions at L-band applied to surface soil moisture retrievals over grass," Remote Sens. Env. 101, 415-426 (2006).

54. T. Pellarin, J.-P. Wigneron, J.-C. Calvet, and P. Waldteufel, "Global soil moisture retrieval from a synthetic L-band brightness temperature data set," J. Geophys. Res. 108, 4364-4830 (2003).

55. H. T. Chuah and T. O. Chong, "Retrieval of soil moisture content from radar backscatter coefficients," IEEE Xplore J. 1, 338-340 (August 1993).

56. M. Ushada, H. Murase, and H. Fukuda, "Non-destructive sensing and its inverse model for canopy parameters using texture analysis and artificial neural network," Comput. Electron. Agri. 57, 149-165 (2007).

57. T. Lakhankar, H. Ghedira, M. Temimi, M. Sengupta, R. Khanbilvardi, and R. Blake, "Nonparametric methods for soil moisture retrieval from satellite remote sensing data," J. Remote Sens. 1, 3-21 (2009).

58. H. Ghedira, T. Lakhankar, N. Jahan, and R. Khanbilvardi, "Combination of passive and active microwave data for soil moisture estimates," IEEE Int. Geosci. Remote Sens. J. 4, 2783-2789 (2004).

59. R. Bindlish and A. P. Barros, "Sub-pixel variability of remotely sensed soil moisture: an inter-comparison study of SAR and ESTAR," IEEE Xplore J. 40(2), 326-337 (February 2002). 
60. C. Notarnicola, M. Angiulli, and F. Posa, "Use of radar and optical remotely sensed data for soil moisture retrieval over vegetated areas," IEEE Trans. Geosci. Remote Sens. J. 44(4), 925-935 (April 2006).

61. S. S. Haider, S. Said, U. C. Kothyari, and M. K. Arora, "Soil moisture estimation using ERS-2 SAR data: a case study in the Solani River catchment," Hydrol. Sci. J. 49(2), 323-334 (April 2004).

62. S. Said, U. C. Kothyari, and M. K. Arora, "Soil moisture estimation from ERS-2 SAR data in Solani River catchment," Agri. Hydrol. Appl. Remote Sens. J. 6411, 1-11 (2006).

63. M. Sprintsin, D. G. Blumberg, J. B. Asher, J. Daniels, and M. Linetsky, "Estimation of soil water content in the Negev desert open areas using archived ERS SAR images," IEEE Xplore J. 4, 2220-2222 (2002).

64. S. Said, U. C. Kothyari, and M. K. Arora, "ANN-based soil moisture retrieval over bare and vegetated areas using ERS-2 SAR data," J. Hydrol. Eng. (June 2008).

65. J. Wen, Z. Su, and Y. Ma, "Determination of land surface temperature and soil moisture from tropical rainfall measuring mission/microwave imager remote sensing data," $J$. Geophys. Res. 108(D2), 4038 (January 2003).

66. Y.-A. Liou, S.-F. Liu, and W.-J. Wang, "Retrieving soil moisture from simulated brightness temperatures by a neural network," IEEE Trans. Geosci. Remote Sens. J. 39(8), 1662-1672 (2001).

67. A. Della Vecchia, P. Ferrazzoli, J.-P. Wigneron, and J. P. Grant, "Modeling forest emissivity at L-band and a comparison with multitemporal measurements," IEEE Trans. Geosci. Remote Sens. J. 4, 508-512 (October 2007).

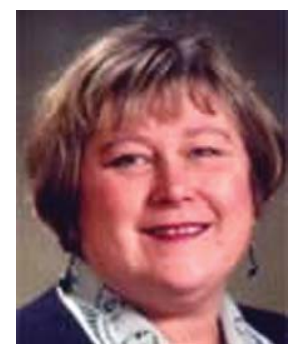

Sue Nichols is a professor and director of graduate studies in the Department of Geodesy and Geomatics Engineering at University of New Brunswick (UNB). She specializes in four primary areas: land policy issues including environment and disadvantaged groups; land administration and development of effective land titling and registration systems; capacity building in a variety of forms at the community, organizational, and academic levels; and ocean governance and coastal zone management. She holds a BSc (Hon) in mathematics from Acadia, a land survey diploma from Nova Scotia Land Survey Institute, and an MEng and PhD in surveying engineering from UNB. Her research includes over 20 years of field experience in Canada, southern Africa, eastern Europe, and central Asia; Latin America, and Southeast Asia. Recent projects include land administration in Brazil and community-based climate-adaptation strategies in Canada and the Caribbean using voluntary geographic information and LIDAR.

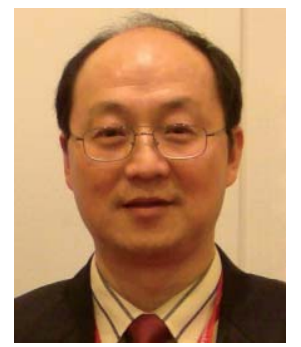

Yun Zhang is Canada research chair in advanced geomatics image processing and a professor in the Department of Geodesy and Geomatics Engineering at the University of New Brunswick. He received his $\mathrm{PhD}$ in remote sensing from the Free University of Berlin in 1997. He is the sole inventor of two patented technologies and co-inventor (with his students) of three patent-pending technologies. Many innovative technologies developed by him and his research group have been licensed to several internationally leading imaging and mapping companies. One of the technologies was selected as one of nine Canadian successful research achievements for "Technology Transfer Works: 100 Cases from Research to Realization" by the Association of University Technology Managers. He is the author of more than 30 of peer-reviewed journal papers and more than 100 refereed conference papers. He is also the recipient of the Talbert Abrams Grand Award of ASPRS and the John I. Davidson President's Award of ASPRS, and he is a nominee for the university teaching award. 


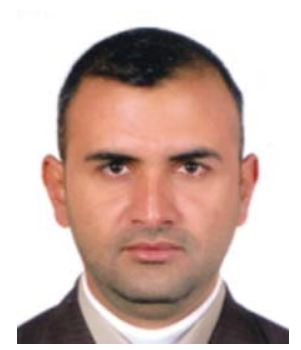

Amer A. Ahmad is an MSc student at the Department of Geodesy and Geomatics Engineering at the University of New Brunswick. He received his BSc from the Department of Civil Engineering at Al-Mustansiriya University in Baghdad in 2003. His current study includes remote sensing and GIS development, and his MSc research is focused on estimating soilmoisture information from optical imagery (using MODIS imagery). He is a student member of the American Society for Photogrammetry \& Remote Sensing "ASPRS" journal. 